\section{Building the modern main-frame}

\section{John Hendry}

The Computer Comes of Age: The

People, the Hardware, and the Software.

By R. Moreau. Translated by Jack

Howlett.

MIT Press: 1984. Pp.227.

$\$ 19.95, £ 20.85$.

THERE are remarkably few books on the recent history of computing. Accounts of the prehistory, from Babbage to the Second World War, abound, as do reminiscences of the pioneering wartime and immediate post-war projects. A start has even been made - for example by Nancy Stern in From ENIAC to UNIVAC - on a genuinely historical analysis of these projects. But there is still precious little on events since 1950 , and virtually nothing in accessible book form.

The Computer Comes of Age, a translation of René Moreau's 1981 book Ainsi Naquit l'Informatique (French birth corresponding, apparently, to English adulthood!), is the first significant exception to this rule. The work is a chronicle rather than a history and the style of presentation, though an improvement on the French edition, does not make for easy reading. The report-like format, with short headed sections, many only a paragraph long, makes few concessions to narrative continuity. Indeed, as one advances through the book and the technological developments, all of which are explained for the benefit of the nonspecialist, get more complex, one becomes increasingly aware of a similarity with computer training manuals. The focus is almost wholly on the technology, with nothing on the social or economic aspects of computer development, and because the work is based largely on "common knowledge" rather than historical research it is far from being authoritative. Finally, even Moreau closes his account with the arrival of the IBM series 360 computers in 1963, a recent event by normal historical standards, but a very distant one if one considers how much has happened since that time.

In short, then, this is not really a book for casual reading, for those interested more in the computer age than in the computers (and computing languages) themselves, or for those seeking a definitive history. Nonetheless, within its very reasonable limits it is a valuable work.

The strength of the book lies in its comprehensive coverage of the myriad of technical developments leading up to what was, in effect, the modern main-frame computer. From ferrite-core memories to front-end processors and from non-local concurrency to the characteristics of COBOL, pretty well every important development of the period is covered, be it in hardware, software, peripherals or operating methods. Almost all the most interesting computers of the period are described, albeit briefly, with mention of their particular innovations and the degrees to which they incorporated emergent technologies. The often-neglected problems of operation and communication, and the development of programming languages, are also brought in.

It is, however, a pity that the laudable effort to make the subject accessible could

\section{Principle patterns}

\section{Brian Goodwin}

\section{Pattern Formation: A Primer in}

Developmental Biology.

Edited by George M. Malacinski and

Susan V. Bryant.

Macmillan, New York/Collier-Macmillan, London: 1984. Pp.626. \$58, £55.

GEORGE Malacinski and Susan Bryant have brought together an excellent collection of essays on pattern formation. No volume could be comprehensive and definitive in such a diverse and rapidlymoving field, but this one comes close. Not only is the range of organisms treated very extensive, from the ciliate protozoa and Volvox to higher plants and animals (though nothing on mammals!); but the conceptual scope is also broad, including work informed largely by classical embryological concepts, sophisticated analytical treatments by the modelbuilders, and detailed analyses of the cellular, genetic and molecular mechanisms involved in pattern formation. Few subjects can boast such an apposite pluralism, for the whole organism together with all its parts continue to exist as real structures in developmental biology. Dominant themes nevertheless come and go. Pattern Formation celebrates a period of research whose intellectual liveliness, balance between empirical discovery and conceptual interpretation, and sheer enjoyability owe much to the personality of one individual, Lewis Wolpert. It is a further tribute that this volume has within it not only material that derives directly from his work, but indications of what type of analytical framework may supersede it.

The book starts with summaries of discussions between Malacinski and some of the contributors, the first of whom states that Wolpert's theory of positional information is not a falsifiable theory, but a concept, a framework for the interpretation of phenomena. In his article with Stein, however, Wolpert says that "the concept of positional information was explicitly formulated by Driesch", arising from his observation that sea urchin blastomeres are not have been accompanied by a similar effort to make it attractive; as it stands, the book is unlikely to appeal greatly to the computer-non-literate population for whom it was apparently intended. But the fact is that no one has yet done any better, or even anywhere near as well in tackling the subject. Until they do, René Moreau's book well deserves whatever success it may find.

John Hendry is the ESRC Fellow in Business History at the London Business School, and is currently preparing a history of the British computer industry.

totipotent, their actual fates therefore depending upon their spatial relations to other cells in the embryo. This was a testable theory, and my understanding is that Wolpert takes the same view of his particular formulation of Driesch's proposition. Certainly, several contributors treat it as such and test it critically against empirical evidence. It is worth noting in passing that in converting Driesch's concept of relational spatial order into the notion of a coordinate system within the organism, Wolpert constructed a conceptual framework, via the notion of free and unconstrained interpretation of "positional values" by species-specific genetic programmes, which opened the door wide to the Darwinian principle that any organismic form is possible, natural selection then making its choice from the continuum. Driesch vehemently opposed this view, planting his banner firmly with the rational morphologists and "laws of form".

Accounts of the search for generative rules or laws operating during development occupy a significant part of this volume, as Susan Bryant observes in her introductory comments. This reflects an important transition in the evolution of positional information models from their early, virtually unconstrained form to ones embodying abstract generative rules such as those of the polar coordinate model (well represented in articles by Held and Bryant on Drosophila, and by French, Holder and Javois on insect, amphibian and chick limbs respectively). Perhaps the most significant consequence of this model is its demonstration that simple rules with empirical consequences can be formulated without reference to molecules, or even cells, capturing principles of spatial organization that extend across an impressive range of taxa. The ingenious application by Frankel of these principles to the explanation of supernumerary oral apparatuses with reversed symmetry in Tetrahymena reminds us that pattern formation is not, in fact, dependent upon cellular interactions. Thus we seem to catch a glimpse of universal principles, the general spatial properties of which are developed with characteristic incision by Winfree.

The richness of morphogenesis, analytically explored in "simple" forms such as Volvox (Sumper), Dictyostelium 